\title{
THE HAEMATOLOGY OF LIVER DISEASE
}

\author{
Morag Chisholm \\ Department of Hacmatology. Soutsampton General Hospital. \\ Soutbampton England.
}

In the early weeks of foetal development the liver is the main site of production of red cells, white cells and platelets. With increasing maturity of the foetus, this function is taken over by the bone marrow, but the liver still retains a potential for haemopoiesis even in adult life. After birth the major active role of the liver in relation to the blood is in the destruction and removal of red cells, and the synthesis of coagulation factors and transferrin, the carrier protein for iron. It is an important storage organ for Vitamin $\mathrm{B}_{12}$ and to a lesser extent folic acid and iron.

The main haematological consequence of liver disease is the development of red cell abnormalities and anaemia due to a variety of causes; white cell changes occur less commonly and are rarely of diagnostic importance. Coagulation abnormalities and thrombocytopaenia are frequently found in liver disease and may present problems in patient management.

\section{ANAEMIA IN LIVER DISEASE}

Because of case selection in reported series it is difficult to assess the frequency of anaemia in liver disease, and to know to what extent the different types occur. Combined results in a number of studies (Deller, et al, 1965; Jarrold \& Vilter, 1949; Klipstein and Lindenbaum, 1965; Krasnow et al 1957) indicate that approximately one third of patients with biopsy documented disease will be anaemic.

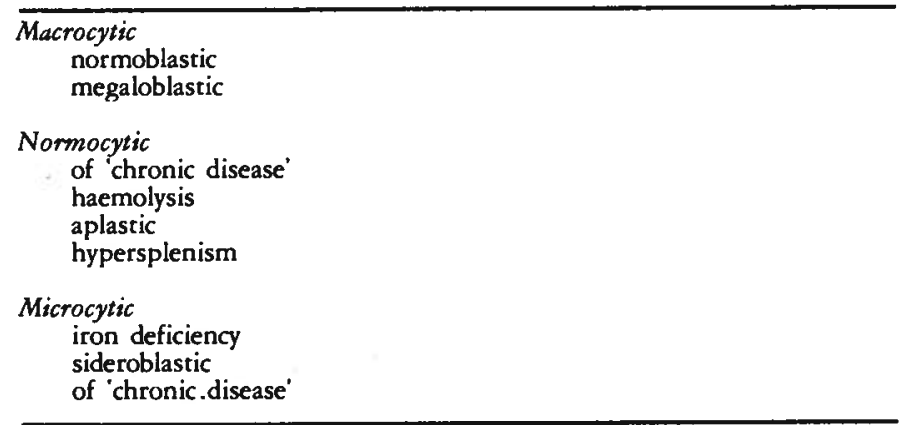


Table I lists the types of anaemias which may be encountered, macrocytic or normocytic pictures being seen more frequently. When anaemia develops it is usually only moderate but it may be severe under certain circumstances, for example blood loss, acute haemolysis and folic acid deficiency. Red cell abnormalities without anaemia are a common occurrence.

\section{MACROCYTIC ANAEMIA}

Macrocytosis has been reported in as many as 60 per cent of patients with liver disease but there may be no accompanying anaemia. (Bingham 1960, Werre, et al 1970). Early workers in the field distinguished two types of macrocytes. Thin macrocytes were flattened cells with an increased diameter and were associated with normoblastic or macronormoblastic erythropoiesis. The second type, originally described as true macrocytes, had an obvious increase in cell volume and were associated with megaloblastic erythropoiesis. With electronic cell counters it is now apparent that even thin macrocytes have some increase in mean cell volume and the distinction is no longer important. The fundamental factor is whether erythropoiesis is normoblastic or megaloblastic.

Macrocytosis with normoblastic maturation was noted in one third of Bingham's patients with various liver disorders and resolved when liver function improved rather than with treatment with folate. Increased red cell membrane cholesterol has been found in thin macrocytes (Neerhout, 1968; Werre et al, 1970) and an increased cholesterol: phospholipid ratio (C P ratio) may cause broadening and flattening of the red cell. Other causes of macrocytosis with a normoblastic bone marrow include erythroid hyperplasia and reticulocytosis associated with haemolysis (Kilbridge \& Heller, 1969). Macrocytosis as a result of a direct toxic effect on erythropoiesis is a common finding in chronic alcoholics (Wu, et al, 1974).

Macrocytosis with megaloblastic erythropoiesis is much less common and in one prospective study of 350 patients with cirrhosis where bone marrow biopsy was performed in all patients who became anaemic was noted in only $2 \%$. (Krasnow et al 1957). It is almost always due to a deficiency of folate and is usually seen in patients with alcoholic liver disease. In this condition abnormalities of folate metabolism occur and a low serum folate level has been reported in approximately $50 \%$ of patients with established disease. (Deller et al, 1965; Klipstein \& Lindenbaum, 1965; Herbert et al 1963). Low red cell folate levels, indicating folate deficiency of some duration (Hoffbrand, 1972), and reduced hepatic folate are also reported in alcoholism (Leevy, et al, 1965). Associated dietary deficiency is the major cause of the folate deficiency and folic acid is the treatment of choice but there is evidence indicating that it is not a simple nutritional deficiency. This topic will be considered in more detail when alcoholic liver disease is discussed.

Disturbances of Vitamin $B_{12}$ metabolism are uncommon and serum levels are usually normal or occasionally raised in patients with hepatocellular damage (Retief et al, 1969). Treatment with Vitamin $\mathbf{B}_{12}$ is not required in the megaloblastic anaemia associated with liver disease.

\section{NORMOCYTIC ANAEMIA'}

\section{(I) The Anaemia of Cbronic Disease}

Chronic disorders such as renal failure and malignant disease can cause a moderate anaemia which is usually normocytic and normochromic, occasionally hypochromic and microcytic. This is referred to as the anaemia of chronic disease and may cause 
anaemia in patients with cirrhosis of the liver. Although the pathogenesis is not clear, iron utilization is impaired and both the serum iron and transferrin levels are reduced unlike the findings in iron deficiency anaemia. Reticuloendothelial (R.E.) iron is increased in the bone marrow but the developing red cells show reduced iron content, the R.E block of chronic disease (Lipschitz et al 1974). Anaemia is usually moderate and does not respond to iron. Control of the underlying disease will improve the haemoglobin level; blood transfusion is not indicated in most cases since the benefit is transient and anaemia is not usually severe.

More commonly in chronic liver disease the serum iron is normal or raised (Chiandussi et al, 1964) and the transferrin level normal or low. Raised ferritin levels have been reported in acute liver damage, possibly because of release from liver cells. (Prieto et al 1975) and increased iron absorption is present in some patients with cirrhosis. (Williams, et al 1967).

\section{(II) Haemolvtic Anaemia}

Low grade haemolysis is frequently present in liver disease but anaemia is not common because the bone marrow compensates by increased erythropoiesis. A moderate reticulocytosis is commonly seen in patients with chronic liver disease (Jarrold \& Vilter, 1949). Features suggestive of haemolysis such as raised serum bilirubin, reduced or absent haptoglobins and shortened red cell survival are found in liver disease without anaemia and their significance should anaemia develop may be difficult to assess.

Certain red cell abnormalities which may be associated with haemolysis are noted frequently, (see Table 2). The normal mature red cell is a biconcave disc and the membrane $C P$ ratio is an important factor in maintaining normal red cell shape. In liver disease the cholesterol and phospholipid content of the plasma may rise in variable proportions leading to an increased erythrocyte content of both and possibly an altered ratio (Cooper 1970). Target cells (so called because of their characteristic target shape on dried films) have a proportionally greater rise in membrane phospholipid and the $C P$ ratio is not much raised; they are commonly seen in the blood of patients with obstructive jaundice (Cooper, et al, 1975).

Table 2

Red Cell Abnormalities seen in Liver Disease
Macrocytes
Target cells
Stomatocytes
Acanthocytes

Stomatocytes, red cells in which the central circular area is replaced by a mouth like unstained area, are noted in alcoholic liver disease; elevated membrane lecithin as well as abnormalities in red cell enzyme content have been reported in the hereditary form (Wiley et al 1975). Acanthocytes, irregularly shaped red cells with multiple spicules (2 to 10 in number), are seen in the blood of patients with established liver disease which again is usually alcoholic in origin; they have a marked increase in C P ratio due to increased membrane cholesterol (Cooper, et al 1972). Several haemolytic syndromes are described in chronic liver disease (Table 3) although the concept that they are distinct from each other has been challenged (Lindenbaum 1977). 
Table 3

Haemolytic Syndromes in Liver Direase
Zieve's Syndrome
'Spur cell' anaemia
Autoimmune

a) Ziev'e's Syndrome - Zieve (1966) described a syndrome usually precipitated by alcohol, characterised by low grade fever, self limiting haemolysis and hyperlipaemia. The patients are not acutely ill and spontaneous recovery occurs; associated hepatomegaly is due to fatty infiltration. The blood picture shows increased polychromasia, some spherocytosis and other red cell abnormalities. A recent study suggests that alcohol induces Vitamin E deficiency and together with altered membrane lipid composition result in pyruvate kinase instability and acute haemolysis (Goebel et al, 1977). Zieve distinguished his syndrome from the picture seen in advanced liver disease in which a significantly enlarged spleen is associated with haemolytic anaemia and reduced platelet and leucocyte counts i. e. the hypersplenic syndrome. Severe cirrhosis was noted on liver biopsy and the condition persisted. Management of this group was more difficult, treatment being aimed at improving the underlying liver disease. In selected patients splenectomy would be considered.

b) Spur cell anaemia - An acute haemolytic anaemia associated with acanthocytosis, the so called spur cell anaemia, is seen rarely in patients with advanced cirrhosis usually secondary to alcohol (Lindenbaum 1977). The development of the acanthocytosis is irreversible and normal red cells acquire the defect on contact with plasma from patients with cirrhosis and acanthocytosis. An intact spleen is necessary for progression of the condition and normal red cell survival has been reported in patients with the defect who have been splenectomised. (Cooper et al 1974).

c) Auto-immune baemolytic anaemia - This is a rare complication of liver disease described in chronic active hepatitis and primary biliary cirrhosis (Hume et al 1970; Pengelly and Jennings 1971) and acute viral hepatitis (Dacie 1967). The Coombs Direct Antiglobulin test may be positive and in one study of chronic active hepatitis the antibody was usually IgG with Rhesus specificity although other specificities have been reported (Lightwood and Scott 1973). In one large series of 1200 patients with acute viral hepatitis, $2 \%$ developed an auto-immune haemolytic anaemia which presented a few weeks after the onset of the acute illness and was of little clinical significance (Foder \& Tanasescu 1962). Treatment with steroids could be given in severe cases but was usually not required.

\section{(III) Aplastic Anaemia}

Aplastic anaemia is a rare and serious complication of viral hepatitis associated with a high mortality. In a review of 195 patients (Hagler et al 1975) males were more often affected but women had a poorer prognosis, only $8.5 \%$ surviving compared with an overall survival of $15 \%$. Not infrequently the anaemia came on as the patients appeared to be recovering from hepatitis, the mean interval from the onset of the illness being 9.3 weeks. With the onset of pancytopaenia the mean survival time was 11.3 weeks; in some, death occurred more than a year later. There is no evidence that therapeutic measures work but treatment with steroids and androgenic agents will be given in the majority of patients. Transient red cell aplasia has also been reported (Sears et al 1975) and it is likely that transient bone marrow depression occurs more commonly than severe aplasia. Bone marrow transplantation has been tried in patients with some success (Thomas et al 1977) and may offer the best chance for severely affected patients. 


\section{Hypersplenism}

Chronic liver failure is often associated with portal hypertension, hypersplenism and an increased plasma volume and this may result in anaemia, thrombocyropateniad and leucopaenia. Splenic sequestration as well as haemodilution contribute to these abnormalities. In one study of patients with chronic liver disease (Sheehy and Berman 1960) an apparent anaemia as defined by a fall in the venous haematocrit was nuted in $70 \%$ but true anaemia as defined by a fall in red cell mass was present in only $40 \%$. Thus, an incresed plasma volume is an important factor contributing to a reduced haemoglobin (Leiberman and Reynolds 1967). Using ${ }^{\text {st }} \mathrm{Cr}$ labelled red cells Toghill \& Green (1979) showed that anaemia was rarely due to excessive splenic pooling and destruction. On the other hand, these factors were shown to be an important cause of the thrombocytopaenia, noted in $13 \%$ of their 187 patients, and ilso leucopatni.t although the latter is more difficult to evaluate.

Treatment of the portal hypertension by portacaval shunt is associated with some haematological improvement in approximately one third of cases (Mac Pherson and Innes 1953, Toghill and Green 1979) but more consistent improvement is reported after splenectomy.

\section{MICROCYTIC ANAEMIA}

In established liver disease uncomplicated by blood loss the serum iron is usually normal or raised (Chiandussi, et al 1964) the transferrin normal or low and transferrin saturation increased. In acute liver damage, serum and ferritin levels are raised (Prieto, et al 1975) possibly because of release from liver cells. Increased iron absorption is documented in patients with cirrhosis, (Conrad, et al 1962, Williams et al 1974). The mechanism is poorly understood; possible explanations include chronic pancreatitis, a direct effect of alcohol on iron absorption and iron overload as a consequence of defective erythropoiesis or haemolysis.

\section{(I) Iron Deficiency Anaemia}

In chronic liver disease uncomplicated by gastrointestinal haemorrhage or a bleeding diathesis, iron deficiency is not common since iron absorption is usually increased. Iron deficiency anaemia in patients with liver disease is likely to be secondary to chronic blood loss which may not always be obvious. In one series, a hypochromic microcytic anaemia was rare in the 46 patients studied although half had excessive blood loss in the stools (Kimber et al 1965). Other workers (Williams et al 1967) state that iron deficiency anaemia is common, but definitive data is lacking.

\section{(II) Sideroblastic Anaemia}

Sideroblastic anaemia is an uncommon complication of liver disease and is usually due to alcohol. Iron utilization is impaired and there is an increase in the serum iron, transferrin saturation and erythroblast and reticuloendothelial iron in the bone marrow. Despite this the red cells may be hypochromic and microcytic.

The basic defect is in haem synthesis and defective production of pyridoxal phosphate, a mitochondrial enzyme essential for haem production has been implicated in some cases. As a result iron accumulates in the red cell where it may lie randomly in the cytoplasm or in the mitochondria encircling the nucleus forming a ring sideroblast. 
Large number of ring sideroblasts are found in the bone marrow of chronic alcoholics but will disappear with abstinence or intravenous administration of pyridoxal phosphate. (Hines and Cowan 1970).

\section{(III) Anaemia due to Chronic Disease}

We have seen that liver disease may lead to a moderate anaemia which is usally normochromic and normocytic. In severe cases it may be hypochromic microcytic and difficult to distinguish from iron deficiency. Bone marrow examination shows reduced iron in the developing red cells but increased reticuloendothelial iron, indicating the $R$. E. Block of chronic disease (Lipschitz, et al 1974). The clinical picture is usually dominated by the underlying disease process and treatment is aimed at the underlying condition. Iron therapy is usually ineffective and blood transfusion is not indicated in most cases since it will only achieve a temporary correction of the anaemia.

\section{LIVER DISORDERS WITH SPECIFIC HAEMATOLOGICAL FEATURES}

The features associated with the particular liver disorders listed in Table 4 will now be described.

Table 4

Liver disorders with specific baematological features

Acure viral hepatitis

Alcoholic liver disease

Hepatocellular carcinoma

\section{ACUTE VIRAL HEPATITIS}

Significant anaemia is a rare complication of acute viral hepatitis and leucocyte and platelet abnormalities are noted much more frequently; mild transient anaemia is not uncommon however (Conrad et al 1964). Abnormalities in the peripheral blood are common; macrocytosis is often present by the time jaundice is clinically present and persists until recorery. Leucopaenia develops before the onset of jaundice (Havens and Marck 1946) but by the seventh to fourteenth day the white count returns to normal. Initially there is both a lymphopaenia and neutropaenia but by the second week there is often a lymphocytosis (Conrad et al 1964). Atypical mononuclear cells seen during the week are of the type commonly seen in viral infections. The platelet count is usually normal or even raised but transient thrombocytopaenia has been reported. By the time the disease is established, the ESR is moderately elevated in the majority of patients particularly in HBsAg negative infections (Vahrman 1971).

Haemolytic anaemia is an uncommon complication of acute viral hepatitis and, as we have seen, may develop in approximately $2 \%$ of patients some weeks after the onset of the disease and is not usually of clinical significance. The use of steroids may be considered if the anaemia is severe. The pathogenesis is not clear; the DCT may be positive and red cell antibodies have been demonstrated. A mild reticulocy tosis and moderate shortening of the red cell survival is reported; the fragility is normal.

Prolonged hyperbilirubinaemia following acute viral hepatitis is described and in part may be due to haemolysis; impaired hepatocellular function or slow resolution of 
the hepatitis may be contributory factors. Aplastic anaemia is another rare complication of viral hepatitis, the main features having been presented previously. The underlying mechanism is poorly understood and in many cases the hepatitis was improving or had resolved when striking pancytopaenia developed (Hagler, et al 1975). Failure of the liver to detoxicate intermediary metabolites or drugs, direct viral-induced bone marrow damage, virally initiated auto-immune mechanisms and individual susceptibility have all been considered.

\section{ALCOHOLIC LIVER DISEASE}

Excessive intake of alcohol will have a direct toxic effect on blood and bone marrow; red cell, white cell and platelet production may all be affected. Provided caloric and vitamin intake is maintained the haematological sequelae of alcoholism are usually not marked (Lindenbaum and Lieber 1969) the major effect being mediated through associated factores such as impaired nutrition, vitamin deficiency and altered liver function. The extent to which the haemopoietic abnormalities reported in alcoholic liver disease are due to direct toxicity of alcohol or to the associated nutritional deficiencies has long been debated. It is now clear that both mechanisms operate. The diet of alcoholics who develop megaloblastic anaemia may be similar to that of patients who do not (Jandle and Lear 1956) and removal of alcohol can result in bone marrow recovery and a return to normoblastic erythropoiesis even though a folate deficient diet is confirmed. (Sullivan and Herbert, 1964). The metabolic block produced by alcohol has been studied (Bertino et al, 1965 Lane et al 1973) but is not clearly understood; it is possible that alcohol impairs absorption of folic acid by the gut mucosa (Halsted, et al 1973).

Alcohol is also known to result in significant abnormalities of iron metabolism producing a raised serum iron, increased transferrin saturation and an increase in R.E. iron stores; these changes are rapidly reversed by withdrawal of alcohol. A metabolic block in the conversion of pyridoxine to pyridoxal phosphate may be a factor (Hines and Cowan 1970) but the picture is obviously complex.

The peripheral blood findings are summarised in Table 5. Macrocytosis is common in patients with alcoholic liver disease being reported in nearly $90 \%$ of chronic alcoholics (Wu, et al 1974) and macrocytosis without anaemia should alert the clinician to the possibility of alcohol abuse (Wright, and Ree 1978). The MCV is moderately raised with Coulter S values of 97 to 105 fl. Most patients have normal folate levels (Wu et al 1974) and the macrocytosis disappears on alcohol withdrawal; folate supplementation will not correct the macrocytosis. The pathogenesis is not clearly established but a direct toxic effect and red cell membrane changes resulting from increased plasma cholesterol levels are both implicated. Stomatocytosis is a transient phenomenon associated with acute alcoholism in approximately $25 \%$ of patients in one study (Douglas \& Twomey 1970) and occasionally there may be associated haemolysis. When acute haemolytic anaemia complicates alcoholic liver disease, acanthocytosis may be present and increased cholesterol and altered membrane lipids play a part in the development of these abnormalities although the exact pathogenesis is not understood.

The bone marrow changes noted in acute alcoholism are striking and occur frequently (Mac Curdy et al 1962) Table 6. Vacuolation of the erythroid precursors and to a lesser extent the myeloid precursors which rapidly disappears after alcohol withdrawal is well described. The chemical nature of the vacuoles has not been clarified, but under the electron microscope, they are seen to be formed by a process of red cell membrane invagination, suggesting a direct toxic effect of alcohol on the cells (Yeung, et al 1973). 
Eichner and Hillman (1971) studied 65 patients with chronic alcoholism and concluded that the bone marrow changes and development of anaemia take place in a predictable fashion. Initially, reduced dietary intake and excessive alcohol lead to a marked drop in serum folate levels and after 1 to 3 weeks the red cell folate falls (Herbert et al 1963) and erythropoiesis becomes megaloblastic and then sideroblastic (Lindenbaum and Lieber 1969). Adequate iron stores are essential for the development of this picture and recovery rapidly takes place with a normal diet or abstinence from alcohol and vacuolation and iron overload will disappear. Five to ten days after stopping alcohol the bone marrow will show erythroid hyperplasia and the reticulocyte count will be raised; the picture at this stage is indistinguishable from haemolytic anaemia. Folic acid is the haematinic of choice and will correct the megaloblastic picture. Haemolytic anaemia and the distinct haemolytic syndromes have been discussed previously. Other causes of anaemia such as iron deficiency due to gastrointestinal blood loss, hypersplenism and dilutional anaemia are all described in cases of chronic alcoholic liver disease (Lindenbaum 1977). The effect of alcohol on the white cell series is less well described. Vacuolation of the white cell precursors and the mature cells in the peripheral blood (Jarrold, et al 1967) and neutropaenia (Liu 1973) is described with an impaired leucocyte response to infections (Mc Farland and Leibre 1963) have been reported. There appears to be an increased susceptibility to infection particularly pneumonia (Berkowitz, et al 1973) Impaired granulocyte response to acute bacterial infection (Chomet and Gach 1967, Mc Farland and Leibre 1963), defective R. E. clearance of organisms (Triger, et al 1972), a direct toxic effect of alcohol on granulocyte mobilization (Brayton, et al 1970) and defective cellular immunity (Berenyi et al 1974) have all been implicated.

Table 5

Peripberal blood findings in alcobolism

1. Red cell changes
macrocytosis
stomatocytosis
acanthocytosis
2. White cells
Neutropienia
Altered neutrophil function
3. Platelets
Thrombocytopaenia
Altered function

Table 6

Bone marrou changes in alcoholism

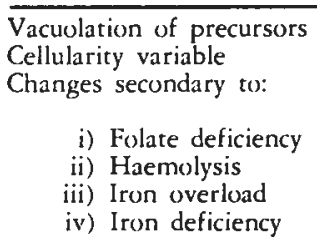

Impaired megakaryocytopoiesis 
A direct toxic effect on the marrow may cause the thrombocytopaenia noted in acute alcoholism. Long standing alcohol intake will cause thrombocytopaenia in most patients, counts between 50 and $100 \times 10^{9}$ being common, and alcoholism may be the commonest cause of thrombocytopaenia in the United States (Cowan and Hines 1971). Reduced platelet survival may be a contributory factor. On resuming a normal diet with alcohol abstinence the platelet count rises within two to three days. Failure of the thrombocytopaenia to respond within a week of alcohol withdrawal should suggest some other underlying mechanism. In summary, then, the haematological abnormalities associated with alcoholic intoxication are due both to a direct toxic effect on the bone marrow and to associated nutritional deficiencies.

Anaemia associated with chronic alcoholic cirrhosis is multifactorial; alcohol withdrawal, treatment with folic acid, control of the associated coagulation abnormalities are obvious therapeutic measures which may result in haematological and clinical improvement. The final factor that will determine the outcome is the degree of hepatocellular failure.

\section{HEPATOCELLULAR CARCINOMA AND ERYTHROCYTOSIS}

Erythrocytosis is a well recognised complication of hepatocellular carcinoma being reported in five to ten percent of patients (Mc Fadzean, et al 1958; Tso and Hua 1974). Most hepatomas develop on the basis of pre-existing cirrhosis and the increased plasma volume in this condition may mask an absolute increase in red cell mass. It has been suggested that at haematocrit levels as low as $48 \%$ an increased red cell mass may be present (Kan et al, 1961). Features usually said to favour the diagnosis of polycythaemia vera may be present in these patients; splenomegaly may be present because of the pre-existing cirrhosis, and leucocytosis is reported in on third of cases (Eppstein 1964). An increased platelet count is usual in the erythocytosis complicating hepatocellular carcinoma. Raised plasma erythropoietin levels were noted in about half the patients in a small study but attempts to show that increased amounts of erythropoietin are generated by the liver tumour are not convincing (Thorling 1972) nor has erythropoietin been isolated from normal liver cultures. Increased production by rapidly growing liver tissue of the substrate which is converted by the enzymatic renal factor to active erythropoietin is another theory which has been proposed (Gordon et al 1970).

\section{WHITE CELL ABNORMALITIES}

White cell changes are not common in liver disease and the leucocyte count is usually normal; the specific changes associated with acute viral hepatitis and alcoholic liver disease have been described. Several leucocyte abnormalities are reported in patients with cirrhosis of the liver (Berman et al 1949) including neutrophilia, neutropaenia \& lymphopaenia. In a recent study (Toghill \& Green, 1979) only $11 \%$ of patients with chronic liver disease were leucopaenic and hypersplenism is obviously a contributing factor although the degree of splenomegaly and neutropaenia does not necessarily correlate. Impaired production has been suggested but the bone marrow appearance in cirrhosis does not support this (Berman et al 1949). Leucocytosis as a response to infection, blood loss, haemolysis and malignant infiltration may occur when these complications arise.

\section{PLATELET ABNORMALITIES}

Thrombocytopaenia is commonly found in established liver disease (Donaldson et al 1969, Finkbiner et al 1959) and is usually moderate, the platelet count being above 
the level associated with spontaneous bleeding (more than $30 \times 10^{9} / 1$ ). The reasons for thrombocytopaenia in patients with liver disease include splenomegaly and portal hypertension, the effects of alcohol, acute blood loss, massive blood transfusion with stored bank blood and disseminated intravascular coagulation.

Acute viral hepatitis (Karpatkin et al 1972) and folate deficiency are other conditions which may lead to its development. Commonly the thrombocytopaenia would be a manifestation of hypersplenism and it is not clear why increased platelet production is unable to compensate for the trapping effect since the platelet survival is normal (Aster 1966) or only moderately reduced (Toghill \& Green 1979) and megakaryocytes are present in normal numbers in the bone marrow (Berman et al 1949). Portacaval shunt improves the thrombocytopaenia in a proportion of patients (Mac Pherson and Innes 1953; Sullivan and Tumen 1961).

Abnormal platelet function has been described in association with liver disease and may be suggested by a long bleeding time when the platelet count is not significantly reduced. Impaired platelet aggregation to a number of aggregants has been reported in falminant liver failure (Rubin et al 1977) and cirrhosis (Thomas et al 1967). Fibrin degradation products (FDP's) or fibrin monomer complexes, possibly because of associated DIC and increased fibrinolysis may interfere with platelet aggregation (Thomas et al 1967) but further study is required. Structural abnormalities on electron microscopy have been demonstrated (Rubin et al 1977).

\section{COAGULATION DISTURBANCES ASSOCIATED WITH LIVER DISEASE}

\section{COAGULATION FACTOR PRODUCTION}

By a series of the reactions which begin either.with activation of Factor Xll by contact with exposed subendothelial collagen (intrinsic pathway) or with activation of Factor VII by tissue substances known as thromboplastins (extrinsic pathway) a fibrin clot consisting of closely interwoven fibrin and platelets is formed. Most of the coagulation factors are produced in the liver, have a short life ranging from a few hours to a few days and are reduced in hepatocellular failure. The synthesis of the Vitamin $\mathrm{K}$ dependent factors. II, VII, IX and X, is dependent on normal liver function and on an adequate supply of Vitamin $K$. Vitamin $K$ is obtained from the diet and from the action of intestinal bacteria and its absorption is aided by bile salts. Synthesis of the factors takes place in two steps; firstly production by the liver of the basic precursor proteins which are non-functional. Vitamin $\mathrm{K}$ is essential for the second step and is responsible for the formation of a unique amino-acid, $\gamma$ carboxyglutamic acid, which enables the precursor protein to bind calcium and actively promote coagulation. Of the other coagulation factors, Factor VIII is unusual in that extra-hepatic sites, including other R.E. and vascular endothelial cells, are involved in its synthesis (Bloom et al, 1973). The role of the liver in producing the fibrinolytic factors and inhibitors of coagulation is not defined. An inhibitor of thrombin and plasmin, anti-thrombin III, the heparin co-factor, (AT III) inactivates other coagulation factors including activated forms of IX, X XI and XII and is probably synthesized in the liver.

Other inhibitors such as $\alpha^{1}$ antitrypsin and $\alpha^{2}$ macroglobulin are also altered in liver disease.

Table 7

Coagulation Defects in Liver Disease

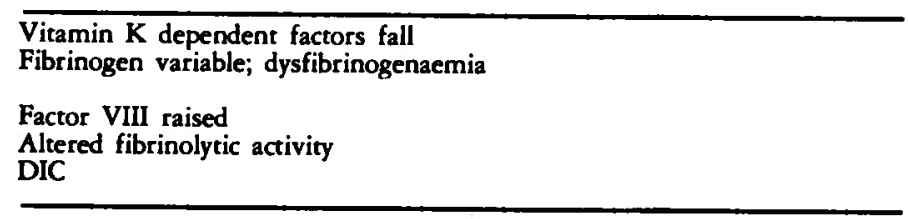




\section{EFFECT ON COAGULATION FACTORS}

\section{(I) Vitamin, $K$ Dependent Factors.}

The earliest eftcut of liver disease on coagulation is a fall in the Vitamin $\mathrm{K}$ dependent factors causing abnormalities of both extrinsic and intrinsic pathways. As a result there is prolongation of the prothrombin time (PT) which assesses the extrinsic pathway and the kaolin or partial thromboplastin time (PTT) used to test the intrinsic pathway.

Two additional tests which are particularly sensitive to deficiency of these factors are the Thrombotest and the Normotest, but in practice these tests are probably no more helpful than the PT alone (Veltkamp and Kruening 1973). The PT is the best screening test for coagulation defects in liver disease (Green et al 1976; Koller 1973); the PTT is usually also prolonged and occasionally may be abnormal when the PT is within the normal range (Donaldson et al 1969; Lee et al 1972).

Factor II, VII, IX and X may be reduced because of hepatocellular failure but also in obstructive jaundice because of malabsorption of Vitamin $\mathrm{K}$. Thus, treatment with Vitamin $\mathrm{K}$ can be used to elucidate the underlying mechanism of the coagulation defect in patients with liver disease; the coagulation abnormality of hepatocellular failure will not be completely corrected by Vitamin $\mathrm{K}$, although some inprovement may occur because a degree of malabsoption is also present.

The PT and PTT may be considered as sensitive liver function tests, occasionally being abnormal while other biochemical tests are within normal limits. With any degree of hepatocellular failure the PT and PTT will be abnormal but bleeding complications not necessarily present (Spector and Corn 1967). In general there is good correlation between coagulation abnormalities and the degree of liver failure. For example, bleeding was noted in three quarters of patients with acute liver failure; (Clark et al 1973) and in some was the direct cause of death. Serial coagulation tests are used to assess progress and prognoșis. In one study of acute liver failure clotting tests rapidly became abnormal and hepatic coma occured in patients whose PT ratio rose above 2.2 (Clark et al 1973). Other workers have showed that the PT ratio was excessively prolonged (greater than 4.8) in all who died (Dymock et al 1975). The Thrombotest is also a valuable prognostic test (Hillenbrand et al 1974). Of specific factor assays Factor VII appears most helpful; it has the shortest half life (approximately 6 hours) and severe reduction (bellow 9\%) was shown to carry a poor prognosis in a small group of patients with acute liver failure (Dymock et al 1975). In chronic liver disease the Factor VII level and the PT correlate well and are equally useful in assessing liver function. The PT and PTT may be normal even when specific coagulation factors are as low as 25 to $30 \%$ of normal although reductions of this order would be unlikely to lead to bleeding complications.

\section{(II) Fibrinogen}

Fibrinogen is an acute phase reactive protein and is raised in response to a variety of stimuli including infection, obstruction and neoplasm. In mild to moderate liver disease fibrinogen levels are normal (Donaldson et al 1969; Tytgat et al 1971) but raised levèls have been reported in obstructive jaundice (Walls and Losowsky 1971) and following extensive liver resection. Reduced levels are described in fulminant liver failure (Clark et al, 1973) and following liver transplantation (Flute et al 1969).

Fibrinogen may be assessed in a number of ways. Quantitative methods such as that of Ratnoff and Menzie (1951) are most accurate but are time consuming; semi-quantitative methods such as clot weight and fibrinogen titre are clinically useful as is the thrombin time. The reptilase time (Funk et al 1971) is also prolonged in hypofibrinogenaemia and shows greater sensitivity to a qualitative abnormality of fibrinogen 
than the thrombin time. A simple colorimetric test using reptilase (Green et al 1976) demonstrated abnormalities of fibrin polymerization in $50 \%$ of patients with advanced liver disease which appeared to be of prognostic significance. It is not certain whether the defective fibrin monomer polymerization is due to a biochemically abnormal fibrinogen molecule; decreased D-galactose content of fibrinogen and an increase in sialic content have been reported (Soria et al 1970). Reduction of the sialic acid content restored normal function to the hepatoma-asseciated fibrinogen (Gralnick, et al 1978).

\section{(III) Factor VIII}

Raised levels of Factor VIII coagulation (C) activity and related antigen ( $\mathrm{RAg}$ ) have been described in a variety of liver disorders including viral hepatitis (Meili and Straub 1970) alcoholic cirrhosis (Green and Ratnoff 1974) and non alcoholic cirrhosis (Outryve et al 1973). Factor VIII is a reactive protein and increased production by the R.E. system in response to a disease process may occur. Release from damaged hepatocytes in acute hepatitis, impaired denaturation and clearance of the Factor VIII molecule by the damaged liver and a response to low grade DIC are other possibilities.

\section{(IV) Other Factors.}

Since Factor $\mathbf{V}$ is synthesized by the liver but is not Vitamin $\mathbf{K}$ dependent, low levels, theoretically, might help distinguish hepatocellular failure from obstructive jaundice. In practice Factor $V$ assay does not appear to be a useful test for this purpose. (Veltkamp and Kreuning 1973). Other factors which may be reduced are the contact factors (Ratnoff 1977) and Factor XIII, the latter being reported as reduced in hepatocellular disease 'Mandel and Gerhold 1969) but not in obstructive jaundice (Walls and Losowsky 1971).

\section{(V) Fibrinolytic activity in liver disease}

Increased fibrinolytic activity has been frequently noted in cirrhosis of the liver (Fletcher et al, 1964; Kwaan, et al 1956) and following surgical resection of the liver (Von Kaulla et al 1966). Decreased fibrinolytic activity has been reported in acute hepatic failure (Clark et al 1973) and in obstructive jaundice (Jedrychowski et al 1973) and the picture is confused. It is generally accepted that increased fibrinolysis is secondary to underlying DIC, triggered off by impaired clearance of activated coagulation products or possibly decreased synthesis of plasminogen (Clark et al 1973). However, increased fibrinolysis could be a primary event induced by circulating plasminogen activators, released by surgery (Fletcher et al 1964), trauma or other precipitating causes. How much the abnormalities described predispose to fibrinolysis and how much they are a consequence of it is difficult to determine. The antiplasmins $\alpha^{1} \alpha^{2}$ macroglobulin are variously reported as reduced and increased in liver disease and AT III reduction has been reported in a variety of liver disorders including chronic liver disease (Mannucci. et al, 1973; Von Kaulla 1967).

Hereditary deficiency of AT III may lead to the development of a hypercoaguable state (Marciniak et al 1974) and low levels in liver disease could predispose to the development of thrombosis.

The concept of intravascular coagulation as a primary event is supported by evidence that heparin can reverse abnormalities such as increased breakdown of fibrinogen (Tytgat et al 1971) and thrombocytopaenia (Horder 1969) in patients with cirrhosis. 
In summary it would seem possible that primary fibrinolysis is operative in situations of acute liver trauma and surgical stress whereas fibrinolysis secondary to DIC is a complication of chronic hepatocellular failure.

\section{(VI) Diagnosis of DIC}

Criteria for the diagnosis of significant DIC are marked prolongation of the PT, PTT and thrombin time, thrombocytopaenia, FDPs greater than $100 \mathrm{mg} / \mathrm{l}$ and a fibrinogen level below $1.0 \mathrm{~g} / \mathrm{l}$. Paracoagulation tests such as ethanol gelation and protamine sulphate tests are used but a high incidence of false positive results has been reported and they do not appear to be helpful in an acute clinical situation (Cash 1977). Assay of platelet release factors is a new development which is under investigation (Ludlam, et al 1975). Many of these tests may be abnormal in patients with liver disease for reasons other than DIC and critical evaluation of the significance of abnormal results is essential.

Evidence of DIC is well documented in patients with liver disease but clinically significant DIC is rare in uncomplicated cirrhosis of the liver (Hillenbrand et al 1974). Other trigger factors may be implicated such as infection, release of endotoxins from the gut (Ratnoff 1977) and liver transplantation (Flute et al 1969) but the exact pathogenesis is not certain.

\section{MANAGEMENT OF THE COAGULATION DEFECT}

The clinical significance of laboratory evidence of a coagulation defect is difficult to assess; many patients with abnormal results may have little or no spontaneous bleeding.

Patients with established liver disease may bleed for many reasons. Haemorrhage may be due to local causes such as oesophageal varices, gastritis and peptic ulceration but the presence of a coagulation defect can aggravate the bleeding tendency. Bleeding may occur because of impaired production of the coagulation factors and/or thrombocytopaenia and occasionally DIC may be a factor. Massive transfusion by stored bank blood lacking coagulation factors and platelets may compound the problem.

\section{a) Bleeding Patients}

Extensive haemorrhage from gastrointestinal lesions such as oesophageal varices and gastric erosions may give rise to a life threatening situation. Local measures to stem the blood loss such as the use of Sengstaken-Blakemore tubes will be tried. Any associated coagulation defect must be treated vigorously. Vitamin $\mathrm{K}$ । by intra muscular injection $10 \mathrm{mgs}$ daily is given for three days although maximum correction of the PT is usually achieved within 24 hours. Persistent abnormality beyond this period indicates hepatocellular dysfunction. The use of F.F.P. and/or prothrombin complex concentrates (P.C.C.) will be necessary to try to correct the defect. F.F.P. would be the therapeutic material of choice in most situations since it contains all the coagulation factors. $10 \mathrm{ml}$ per $\mathrm{kg}$ would be an average initial dose and in fact two units of F.F.P. is usually given in the first instance. Further F.F.P. will be given as required and is often necessary.

Where there are problems of fluid overload the use of P.C.C. will be considered but is not without risk. Early users of P.C.C. in patients with liver disease reported fatal DIC due to the presence of activated products (Blatt, et al, 1974 Gazzard et al 1974). Improved fractionation techniques and better in vitro testing for spontaneous thrombin 
generation (Sas, et al 1975) have made these products safe in patients with liver disease (Green et al 1975; Mannucci et al 1975) but patients with an increased risk of thrombosis, for example a history of a previous thrombosis, should not be given concentrates. The risk of developing hepatitis still remains even with increased sensitivity of techniques to detect the hepatitis B virus and careful screening of all pooled plasma.

The benefit of replacement therapy is often temporary and repeated treatment is often necessary to maintain haemostasis. Blood transfusion with fresh whole blood is to be recommended in severe haemorrhage since rapid replacement with stored bank blood may aggravate the coagulation defect and it is recommended that $5 \%$ to $10 \%$ of any massive transfusion should be by fresh blood. If this service is not available F.F.P. and platelet concentrates, if necessary, should be given.

As a general rule spontaneous bleeding is unusual with platelet counts greater than $30 \times 10^{9} / 1$. Counts below this are uncommon in patients with liver disease unless there are other complications. Marked thrombocytopaenia may be temporarily corrected by platelet transfusion but it is often difficult to achieve a prolonged rise in the platelet count. Defects of platelet function are uncommon and difficult to correct but transfusion of platelet concentrates may be worth trying.

Other measures rarely considered in this situation include the use of plasmaphoresis to replace defective plasma by fresh plasma thus avoiding the problems of circulatory overload. Such measures might tide the patient over a life threatening episode of haemostatic failure but on the whole are little used.

\section{b) The Management of DIC}

Effective treatment of patients with DIC include (i) measures to treat any trigger factors (ii) replacement therapy and (iii) the possible use of measures to stop continuing thrombosis. Trigger factors such as infection, shock, dehydration and vascular stasis must obviously be treated and measures which achieve this may be sufficient to control the condition. Serial laboratory assessment will be important to assess the progress and control of the disease. The use of replacement therapy has been questioned on the basis that the bleeding diathesis is due in part to the presence of breakdown products of fibrin and other activated products, and that replacement of the coagulation factors may add fuel to the fire. However if a bleeding patient has a severe coagulation defect specific therapy will be given. Fresh blood can be given but if not available packed red cells and F.F.P will be given instead. P.C.C. and other concentrates should not be used in DIC. Severe hypofibrinogenaemia may be treated by cryoprecipitate a rich source of fibrinogen and Factor VIII.

If the situation is deteriorating clinically in spite of these measures and there is laboratory evidence of continuing DIC, treatment with heparin will be considered. An uncontrolled study of 20 patients with acute hepatic necrosis treated with heparin and F.F.P. suggested that this might be beneficial (Clark et al 1973) but a later study in paracetamol-induced hepatic necrosis showed no significant difference when F.F.P. was compared with F.F.P. and heparin (Gazzard et al 1974) and the value of heparin has not been proved by any controlled prospective trial The present recommendation would be to reserve this for cases where therapy, as outlined previously, has failed to reverse life threatening haemorrhage or thrombosis. The use of fibrinolytic inhibitors such as tranexamic acid (cyclokapron) either alone or in combination with heparin has been considered for patients where excess fibrinolysis is a major component of the coagulopathy (Poller 1977) but most clinicians would be alarmed at the possible dangers in their use, reserving such treatment for patients where all other measures have failed. 


\section{Preparations for Liver Biopsy}

In patients about to under go liver biopsy or surgery, correction of the coagulation defect is necessary. If it cannot be accomplished, the decision to proceed with operation

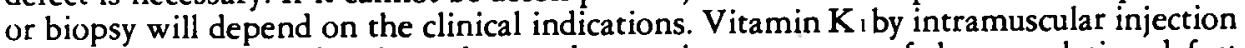
$10 \mathrm{mg}$ daily is given for three days and some improvement of the coagulation defect may occur. If the PT is still outside the normal range then it will be necessary to give coagulation factors either as F.F.P. or P.C.C. in an attempt to correct the defect. As yet no definite regime can be recommended (Green et al, 1975; Mannucci et al 1976). Mannucci and his colleages showed that a combination of F.F.P. ( $8 \mathrm{ml} / \mathrm{kg}$ body weight) and a four factor concentrate $(12 \mathrm{U} / \mathrm{kg}$ body weight) containing all the Vitamin $\mathrm{K}$ dependent factors best corrected the defect in patients being prepared for liver biopsy. A single dose of F.F.P. $(12 \mathrm{ml} / \mathrm{kg})$ was not effective nor was concentrate lacking Factor VII. A MRC trial was set up to compare three factor P.C.C. (10U Factor IX $/ \mathrm{kg}$, body weight) with F.F.P. (5U Factor IX/kg body weight) but limited success was achieved with this dosage. Maximal correction is usually achieved within 15 minutes of the dose and a second dose can be given with some further improvement. It is the experience of most workers that a severe defect cannot be corrected and liver biopsy may not be possible.

Associated thrombocytopaenia is an obvious hazard in patients undergoing liver biopsy and platelet concentrates may be required to cover the biopsy. Provided the bleeding time is normal, moderate thrombocytopaenia is not a contra-indication. The bleeding time is a simple practical manoeuvre which should be performed in any doubtful case; significant prolongation would be considered an absolute contra-indication to elective liver biopsy or surgery.

\section{REFERENCES}

ASTER RH: (1966) Pooling of platelets in the spleen; role in the pathogenesis of hypersplenic thrombocytopaenia. J Clin Investig 45, 645-657.

BERENYI MR, STRAUS B \& CRUZ D: (1974) In vitro and in vivo studies of cellular immunity in alcoholic cirrhosis. Amer J Digest Dis 19, 199-205.

BERKOWITZ H, REICHEL J \& SHIM C: (1973) The effect of ethanol on the cough reflex. Clin Sci Molec Med 45, 527-531.

BERMAN L, AXELROD AR, HORAN TN, JACOBSON SD, SHARP EA \& VON DER HEIDE EC: (1949) The blood and bone marrow in patients with cirrhosis of the liver. Blood 4, 511-533.

BERTINO JR, WARD J, SARTORELII AC \& SILBER R: (1965) An effect of ethanol on folate metabolism. J Clin Investig 44, 1028.

BINGHAM J: (1960) The macrocytosis of hepatic disease. II Thick macrocytosis. Blood 15, 694-707.

BLATT PM, LUNDBLAD RI, KINGDON MS, MCLEAN G \& ROBERTS MR: (1974) Thrombogenic materials in prothrombin complex concentrates.Ann Int Med 81, 766-770.

BLOOM AL, GIDDINGS JC \& WILKS CJ: (1973) Factor VIII on the vascular intima: possible importance in haemostasis and thrombosis. Nat New Biol 241, 217-219.

BRAYTON RG, STOKES PE, SCHWARTZ MS \& LOURIA DB: (1970) Effect of alcohol and various diseases on leukocyte mobilization, phagocytosis and intracellular bacterial killing. New Engl J Med 282, 123-128.

CASH JD: (1977) Disseminated intravascular coagulation. In Recent Advances in Blood Coagulation (Ed.) Poller, L. pp 293-311. Edinburgh, London and New York: Churchill Livingstone.

CHIANDUSSI L, BIANCO A, MASSARO A, MAZZA V \& CESANO, I: (1964) The quantitative determination of iron kinetics and haemoglobin synthesis in anaemia of cirrhosis studied with ${ }^{59} \mathrm{Fe}, B l u t, 10$, 120

CHOMET B \& GACH BM: (1967) Lobar pneumonia and alcoholism: an analysis of thirty seven cases. Amer $J$ Med Sci, 253, 300-304.

CLARK R, RAKE MO, FLUTE PT \& WILLIAMS R: (1973) Coagulation abnormalities in acute liver failure. Scand J Gastroent, (Suppl 8) 19,63-70.

CONRAD ME, BERMAN A \& CROSBY WH: (1962) Iron kinetics in Laennec's cirrhosis. Gastroent 43,

385-390.
CONRAD ME, SCHWARTZ FD \& YOUNG AA: (1964) Infectious hepatitis - a generalised disease. Amer J Med, 37, 789-801. 
COOPER RA: (1970) Lipids of human red cell membrane: normal composition and variability in disease Seminars in Haematology, 7, 296-322

COOPER RA, KIMBALL DB \& DUROCHER JR (1974) Role of the spleen in membrane conditioning and hemolysis of spur cells of liver disease. New Engl J Med, 290, 1279-1284.

COOPER RA, DILOY-PURAY M, LANDO P \& GREENBERG MS (1972) An analysis of lipoproteins, bile acids and red cell membranes associated with target cells and spur cells in patients with liver disease. J Clin Invest. 51, 3182-3192.

COOPER RA, ARNER EC, WILEY JS \& SHATTIL SJ: (1975) Modification of red cell membrane structure by cholesterol-rich lipid disporsions. A model for the primary spur cell defect. J Clin Invest, 55, 115-126.

DACIE JV: (1967) The Haemolytic Anaemias, Part III-Secondary or Symptomatic Anaemias. pp. 826-837. London: J \& A Churchill.

DELIER, DJ KIMBER CL \& IBBOTSON RN: (1965) Folic acid deficiency in cirrhosis of the liver. Amer $J$ Digest Dis, $10,35-42$.

DONALDSON GWK, DAVIES SH, DARG A \& RICHMOND J: (1969) Coagulation factors in chronic liver disease. J Clin Pathol 22, 199-204.

DOUGLAS CC \& TWOMEY JJ: (1970) Transient stomatocytosis with haemolysis: a previously unrecognised complication of alcoholism. Ann Int Med, 72, 159-164.

DYMOCK IW, TUCKER JS, WOOLF IL, POLLER L \& THOMSON JM: (1975) Coagulation studies as a prognostic index in acute liver failure. Brit J Heamat. 29, 385-395.

EICHNER ER \& HILLMAN RS: (1971) The evolution of anemia in alcoholic patients. Amer $J$ Med, 50 , 218-232.

EPPSTEIN S: (1964) Primary carcinoma of the liver. Amer J Med Sci, 247, 137.

FLETCHER AP, BIEDERMAN D, MOORE D, AIKJAERSIG N \& SHERRY S: (1964) Abnormal plasminogen plasmin system activity (fibrinolysis) in patients with hepatic cirrhosis. J Clin, Invest, 43, 681-695.

FLUTE PT, RAKE MO, WILIIAMS R, SEAMAN MJ \& CALNE RY: (1969) Liver transplantation in man. IV Haemorrhage and thrombosis. Brit Med J, iii, 20-23.

FODOR O \& TANASESCU R: (1962) Anemiile hemolitice immunologice posthepatice. Med Int (Bucaresti), $14,1469-1476$.

FUNK C, GMUR J HEROLD R \& STRAUB PW: (1971) Reptilase-R. A new reagent in blood coagulation. Brit J Haemat. 21. 43-52.

GAZZARD BG, CLARK R,BORIRAKCHANYAVAT V \& WILLIAMS R: (1974) A controlled trial of heparin therapy in the coagulation defect of paracetamol-induced hepatic necrosis. Gut, 15, 89-93.

GAZZARD BG, LEWIS ML, ASH G, RIZZA CR, BIDWELL E \& WILLIAMS R: (1974) Coagulation factor concentrates in the treatment of the haemorrhagic diathesis of fulminant hepatic failure. Gut, 15 ,
$993-998$.

GOEBEL KM, GOEBEL FD, SCHUBOTZ R \& SCHNEIDER J: (1977) Red cell metabolic \& membrane features in haemolytic anaemia of alcoholic liver disease (Zieve's syndrome). Brit J Haemat. 35, 573-585.

GORDON AS, ZANJANI ED \& ZALUSKY R: (1970) A possible mechanism for the erythrocytosis associated with hepatocellular carcinoma in man. Blood, 35, 151-157.

GRALNICK HR, GIVELBER H \& ABRAMS E: (1978) Dysfibrinogenaemia associated with hepatoma: increased carbohydrate content of the fibrinogen molecule, New Engl J Med, 299. 221-226.

GREEN AJ \& RATNOFF OD: (1974) Elevated antihaemophiliac factor (AHF factor VIII) pro-coagulant activity and AHF - like antigen in alcoholic cirrhosis of the liver. J Lab Clin Med. 83, 189-197.

GREEN G, DYMOGK IW POLLER L \& THOMSON JM: (1975) The use of a factor VII rich prothrombin complex concentrate in liver disease. Lancet, I. 1311-1314.

GREEN G, POLLER L, THOMSON JM \& DYMOCK IW: (1976)a Factor VII as a marker of hepatocellular synthetic function in liver disease. $J$ Clin Pat, 29, 971-975.

GREEN G, THOMSON JM, DYMOCK IW \& POLLER L (1976)b Abnormal fibrin polymerization in liver disease. Brit I Haemat. 34, 427-439.

HAGLER L, PASTORE RA, BERGIN JJ \& WRENSCH MR: (1975) Aplastic anaemia following viral hepatitis. Med, 54, 139-164.

HALSTED CH, ROBLES EA \& MEZEY E: (1973) Intestinal malabsorption in folate deficient alcoholics. Gastroent 64, 526-532.

HAVENS WP \& MARCK RE: (1946) The leukocytic response of patients with experimentally induced infectious hepatitis. Amer J Med Sci. 212, 129.

HERBERT V, ZALUSKY R \& DAVIDSON CS: (1963) Correlation of folate deficiency with alcoholism and associated macrocytosis, anaemia and liver disease. Ann Int Med 58, 977-988.

HILLENBRAND P, PARBHOO SB, JEDRYCHOWSKI A \& SHERLOCK S: (1974) Significance of intravascular coagulation and fibrinolysis in acute hepatic failure. Gut, 15, 83-88.

HINES JD \& COWAN DH: (1970) Studies on the pathogenesis of alcohol-induced sideroblastic bone marrow abnormalities. New Engl J Med, 283, 441-446.

HOFFBRAND AV: (1972) The Red cell Folate Assay M. D. Thesis, University of Oxford. HORDER MH: (1969) Consumption coagulopathy in liver cirrhosis, Thromb Diatbesis Haemor (Suppl.) 36,
313-318. HUME R, WILLIAMSON JM \& WHITELAW JW: (1970) Red cell survival in biliary cirrhosis. J Clin Pat, 23,
$397-401$. 
JANDL JH \& LEAR AA: (1956) The metabolism of folic acid in cirrhosis. Ann Int Med 45, 1027-1044.

JARROLD T \& VILTER RW: (1949) Haematologic observations in patients with chronic hepatic insufficiency. J Clin Invest 28, 286-292.

JARROLD T, WILL JJ \& DAVIES AR: (1967) Bone marrow erythroid morphology in alcoholic patients. Amer J Clin Nutr, 20, 716-722.

KAN YW, MCFADZEAN AJS, TODD D \& TSO SC: (1961) Further observations on polycythaemia in hepatocellular carcinoma. Blood, 18, 592-598.

KARPATKIN S, STRICK N, KARPATKIN MB \& SISKIND GW: (1972) Cumulative experience in the detection of antiplatelet antibody in 234 patients with idiopathic thrombocytopaenic purpura, systemic lupus erythematosus and other clinical disorders. Amer J Med 52, 776-785.

KILBRIDGE TM \& HELLER P: (1969) Determinants of erythrocyte size in chronic liver disease. Blood, 34, 739-746.

KLIPSTEIN FS \& LINDENBAUM J: (1965) Folate deficiency in chronic liver disease. Blood, 25, 443-456.

KOLLER F: (1973) Theory and experience behind the use of coagulation tests in diagnosis and prognosis of liver disease. Scand J Gastr. (Suppl 8), 19, 59-61.

KRASNOW SE, WALSH JR, ZIMMERMAN HJ \& HELLER P: (1957) Megaloblastic anaemia in 'alcoholic' cirrhosis. Arch Int Med. 100, 870-880.

KIMBER C, DELLER DJ, IBBOTSON RH \& LANDER H: (1965) The mechanism of anaemia in chronic liver disease. Quart J Med, 34, 33-64.

KW AAN HC MCFADZEAN AJS \& COOK J: (1956) Plasma fibrinolytic activity in cirrhosis of the liver. Lancet, i, 132-136.

LANE F, GOFF P, MCGUFFIN R \& HIILMAN R: (1973) The influence of ethanol on folate metabolism, Blood, 42, 998.

LEE S, YIP M \& SACHS HJ: (1972) Factor IX deficiency in liver disease. J Am Med Ass. 221, 1410-1412.

LEEVY CM, BAKER H, TENHOVE WW, FRANK O \& CHORNICK GR: (1965) B-complex vitamins in liver disease of the alcoholic. Am $J$ Clin Nutr. 16, 339-346.

LIEBERMAN FL \& REYNOLDS TB (1967) Plasma volume in cirrhosis of the liver. J Clin Invest 46, 1297 -1308 .

LIGHTWOOD AM \& SCO'TT GL: (1973) Auto-immune haemolytic anaemia due to red cell antibodies of different specificities in a patient with chronic hepatitis. Vox Sanginis, 24, 331-336.

LINDENBAUM J: (1977) Metabolic effect of alcohol on the blood and bone marrow. In Metabolic Aspects of Alcoholism. (Ed) Leiber, C.S. pp 215-247. Baltimore: University Park Press.

LINDENBAUM J \& LIEBER CS (1969) Hematologic effects of alcohol in man in the absence of nutritional deficiency. New Engl I Med. 281, 333-338

LIPSCHITZ DA, COOK JO \& FINCH CA: (1974) A clinical evaluation of serum ferritin as an index of iron stores. New Engl J Med 290, 1213-1216.

LIU YK: (1973) Leukopenia in alcoholics. Amer J Med S4, 605-610.

LUDLAM CA, MOORE S, BOLTON AF, PEPPER DS \& CASH JD; (1975) The release of a human platelet specific protein measured by a radioimmunoassay. Thrombosis Research. $6,543-548$.

MACPHERSON AIS \& INNES J: (1953) Peripheral blood picture after operation for portal hypertension, Lancet, i, 1120-1123.

MANDEL EE \& GERHOLD WM: (1969) Plasma fibrin stabilizing factor; Acquired deficiency in various disorders. Amer J Clin Path, 52, 547-556.

MANNUCCI PM, FRANCHI F \& DIOGUARDI N: (1976) Correction of abnormal coagulation in chronic liver disease by combined use of fresh frozen plasma and prothrombin. Lancet. ii. 542-545.

MANNUCCI L, DIOGUARDI N, DEI. NINNO E \& MANNUCCI PM: (1973) Value of thrombotest and antithrombin III in the assessment of liver function. Scand J Gastr, (Suppl. 8) 19, 103-107.

MARCINIAK E, FARIEY CH \& DE SIMONE PA: (1974) Familial thrombosis due to antithrombin III deficiency. Blood. 43, 219-231.

MCCURDY PR, PIERCE LE \& RATH CE: (1962) Abnormal bone marrow morphology in acute alcoholism. New Engl J Med. 266, 505-507.

MCFARLAND W \& LEIBRE EP: (1963) Abnormal leukocyte response in alcoholism. Ann Int Med, 59, 865-877.

MCFADZEAN AJS TODD D \& TSANG KC: (1958) Polycythemia in primary carcinoma of the liver. Blood, 13, 427-435.

MEILI EO \& STRAUB PW: (1970) Elevation of factor VIII in acute fatal liver necrosis. Thrombosis et Diathesis Haemorrhagica (Stuttgart) 24, 161-174.

NEERHOUT RC: (1968) Abnormalities of erythrocyte stromal lipids in hepatic disease. J Lab Clin Med. 71, 438-477.

OUTRYVE M, VAN BAELE G, WEERDI. GA de \& BARBIER F: (1973) Antihaemophilic factor A (FV111) and serum fibrin-fibrinogen degradation products in hepatic cirrhosis. Scand J Haemat. 11, 148-152.

PANGELIY CDR \& JENNINGS RC: (1971) Active chronic hepatitis and haemolytic anaemia associated with Rh-specific antibodies. Postgr Med J, 47, 683-686.

POLLER L: (1977) Coagulation abnormalities in liver disease. In Recent Advances in Blood Coagulation (Ed.) Poller, L. Pp. 266-292. Edinburgh, London and New York: Churchil Livingstone. 
PRIETO J, BARRY M \& SHERLOCK S: (1975) Serum ferritin in patients with iron overload and with acute and chronic liver disease. Gastr 68, 525-533.

RATNOFF OD: (1977) The haemostatic defects of liver disease. In Haemostasis: Biochemistry, Physiology and Pathology (ed. Ogston, D. \& Bennett. B. pp. 446-466. New York: Wiley.

RATNOFF OD \& MENZIE C: (1951) A new method for the determination of fibrinogen in small samples of plasma. J Lab Clin Med. 37, 316-320.

RETIEF FP, VANDEN PLAS I \& VISSER H: (1969) Vitamin B 12 binding proteins in liver disease Haematology. 16, 231-240.

RUBIN MH, WESTON MJ, BULLOCK G, ROBERTS J, I.ANGLEY PG, WHITE YS \& WILLIAMS R: (1977) Abnormal platelet function and ultrastrucrure in fulminant hepatic failure. Ouat $J$ Med. 183. 339-352

SAS G, OWENS RE, SMITH JK, MIDDLETON S \& CASH JD: (1975) In vitro spontaneous thrombin generation in human factor DX concentrates. Brit I Haemat, 31, 25-35.

SEARS DA, GEORGE JN \&GOLD MS: (1975) Transient red blood cell aplasia in association with viral hepatitis. Occurrence four years apart in siblings. Arcb Inter Med, 135, 1585-1589.

SHEEHY TW \& BERMAN A: (1960) The anaemia of cirrhosis. J Lab Clin Med. 56, 72-82.

SORIA J, COUPIER J, SAMAMA M,TIXIER P \& BILSK PG: (1970) Dysfibrinogenaemia without bleeding tendency with abnormal polymerization of fibrin monomers in a case of severe hepatitis. XII Congress of the International Society of Haematology. New York, Abstracts, p. 180.

SPECTOR I \& CORN M: (1967) Laboratory tests of haemostasis. the relation to haemorrhage in liver disease. Arch Int Med, 119, 577-582.

SULIIVAN BH Jr \& TUMEN HJ: (1961) The effect of portacaval shunt on thrombocytopenia associated with portal hypertension. Ann Int Med, 55, 598-603.

SULLIVAN LW \& HERBERT V: (1964) Suppression of haematopoiesis by ethanol. J Clin Invest 43, $2048-2062$.

THOMAS DP, REAM VJ \& STUART RK: (1967) Platelet aggregation in patients with Laennec's cirrhosis of the liver. New Engl J Med 276, 1344-1348.

THOMAS ED, BUCKNER CD, CLIFT RA, PETER A, NEIMAN PE \& STORB R: (1977) Current status of marrow transplantation for leukaemia or aplastic anaemia. In Recent Advances in Haematology (Ed) Hoffbrand, AV, Brain MC \& Hirsh J pp. 111-125. Edinburg. London and New York: Churchill Livingstone.

THORIING EB: (1972) Paraneoplastic erythrocytosis and inappropriate erythropoietin production. Scand J Haemat (Suppl 17) 1, 1, 1660.

TOGHILL PJ, and GREEN S: (1979) Splenic influences on the blood in chronic liver disease. Quart, J Med N. S. 48,613 .

TRIGER DR, ALP MH \& WRIGHT R: (1972) Bacterial and dietary antibodies in liver disease. Lancet, i, 60-63.

TSO SC \& HUA ASP: (1974) Erythrocytosis in hepatocellular carcinoma - a compensatory phenomenon Brit J Haemat, 28, 497-503.

TYTGAT GM, COLLEN D \& VERSTRAETE M: (1971) Metabolism of fibrinogen in cirrhosis of the liver. J Clin Invest, 50, 1690-1701.

VAHRMAN J: (1971) Viral hepatitis and the ESR, Brit Med J. ii, 466-467.

VELTKAMP JJ \& KREUNING J: (1973) Diagnostic value of coagulation studies in chronic liver disease. Scand $J$ Gast, (Suppl 8) 19, 93-95.

VON KAULLA E \& VON KAULLA KN: (1967) Antithrombin III and diseases. Amer J Clin Path, 48, 69-80.

VON KAULIA KN, KAYE H, VON KAULIA E, MARCHIOR TL \& STARZL TE: (1966) Changes in blood coagulation before and after hepatectomy or transplantation in dogs and man. Archives of Sargery. 92, 71-79.

WALLS WD \& LOSOWSKY MJ: (1971) The hemostatic defect of liver disease. Gastrent, 60, 108-119.

WERRE JM, HELLEMAN PW, VERLOOP MC \& DEGIER J: (1970) Causes of macroplania of erythrocytes in diseases of the liver and biliary tract with special reference to leptocytosis. Brit $J$ Haemat, 19, 223-235.

WILEY JS;ELLORY JC, SHUMAN MA, SHALLER CC \& COOPER RA: (1975) Characteristics of the membrane defect in the hereditary stomatocytosis syndrome, Blood, 46. 337-356.

WILLIAMS R, WILLIAMS HS, SCHEUER PJ, PITCHER CS, LOIZEAU E \& SHERLOCK: (1967). Iron absortion and siderosis in chronic liver disease. Quart J Med, 36, 151-165.

WRIGHT SG \& REE GH: (1978) Blood in the alcohol stream. Lancet, i, 49-50.

WU A, CHANARIN I \& LEVI A]: (1974) Macrocytosis of chronic alcoholism Lancet, i 829.

YEUNG KY, KLUG PP, BROWER M \& LESSIN IS: (1973) Mechanism of alcohol induced vacuolization in human bone marrow cells. Blood, $42,998$.

ZIEXE L: (1966) Hemolytic anemia in liver disease. Medicine, 45, 497-505.

Address for reprints: Morag Chisholm

Department of Haematology,

Soutbampton General Hospital

Tremone Road

Soutbampton, SO9 4XY. England. 